\title{
Assessing User
}

\section{Interactions at the Desk Nearest the Front Door}

Some library users come in the door knowing exactly where to go, with clearly defined and communicated needs. However, many more enter the library on an exploratory mission and often stop at the first service desk that catches their eye. In many libraries, this point of first contact is a security or general information desk, not a full-service reference desk. This opens the question, are users being served effectively and their expectations being met? During the first several weeks of the fall 2003 semester, staff at the service desk closest to the front door of a large academic library recorded the specific questions asked by library patrons and their responses. This data was subjected to qualitative analysis techniques and revealed some trends in what current students are seeking when they initially come into the library. The results are useful for managers to consider in establishing appropriate staffing models (such as who should work at this desk), developing relevant training, and planning service desk and collection spatial configurations. This article presents the results from this study and explores possible factors that managers should take into consideration.

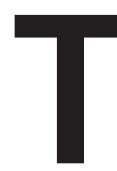

he presence of a service desk within sight of the front door of the library is not a new phenomenon. Depending on the individual library layout, this may be a primary operation desk with senior staff or librarians, such as for circulation or reference. Alternately, in many libraries, the first desk a visitor to the library encounters may be a basic information desk staffed by volunteers, non-library track employees (such as a security monitor), student workers, or less-experienced library support staff. A desk may be visibly designed around a security function, but the expectations of the user coming in the door may force it into a directional assistance role, similar to that of an information desk. Though limited in role, this service point is still a user's first contact point with a representative of the library, and they approach it with questions and expectations of assistance.

The implementation of actual information desks separate from reference desks has been around for the past forty years, with the first real assessment of information desks conducted by Jane Kleiner in 1968 and followed up with a more focused survey conducted by Larry Harrelson in $1974 .{ }^{1}$ A 1978 study at the University of Chicago Library supported the use of non-librarian staff, and

\section{Pixey Anne Mosley}

Pixey Anne Mosley is Professor of Library Science and Head of Access Services, Texas A\&M University Libraries, College Station. Preliminary results from this study were presented as a poster session at the 2004 American Library Association Annual Conference in Orlando, Florida. Submitted for review April 26, 2006; accepted for publication July 3, 2006.

Reference \& User Services Quarterly, vol. 47, no. 2, pp. 159-167 (c) 2007 American Library Association. All rights reserved.

Permission granted to reproduce for nonprofit, educational use. 
suggested that the realistic need for the desk was actually periodic, a few weeks out of every year. ${ }^{2}$ As presented in the 1991 Association of Research Libraries SPEC Kit Information Desks in ARL Libraries, the more extensive use of information desks as part of structured, tiered service models is a fairly contemporary development, as assistance provided from the reference desk became increasingly more sophisticated with the multitude of electronic resources and interdisciplinary research demands. ${ }^{3}$ In this study, 45 percent of the responding eighty-nine libraries indicated having an information desk, but they did not keep statistics on the detailed nature of the questions being asked and the percentage of questions referred to other library service points. The premise behind the information desk model is that of providing tiered service with better resource utilization by having senior staff and librarians spend more time answering in-depth research questions rather than directing students to photocopiers and bathrooms.

Since these early surveys, there have been periodic assessments of the services provided by these desks and the staffing models supporting them. In 1997 , a survey of two hundred library users assessed the effectiveness and user satisfaction with the tiered service model at Texas A\&M University Library. The results of this study raised concerns that user expectations were not consistent with the information desk tiered service model. ${ }^{4}$ In 1998, an article in the Bulletin of the Medical Library Association reported the use of focus groups to evaluate information desk services provided by library support staff. ${ }^{5}$ A subsequent article in the Journal of Academic Librarianship in 2000 presented the results of an analytical study of how library users move between different service points, including those available electronically. ${ }^{6}$ A recent evolution from the information desk/tiered service concept of the 1990s has been the exploration of taking the library to the students and the reconfiguration of many service points to an information commons model. ${ }^{7}$ However, many large libraries do not have the architectural space layout, power and data wiring configuration, and available renovation budget to immediately implement the sort of models presented in these recent studies. These libraries may be trapped in a model where the desk nearest the door is a security or basic informational/directional/referral service model, with considerable variation in staffing across institutions.

Even though in-building use may be reduced from the peaks of previous decades, many people are still coming to the library and asking questions of the first official-looking desk or person they see. As with any interpersonal interaction, this first impression has a direct impact on how the user will perceive the library as a whole and is a critical factor in exploring quality of service issues. Are users approaching this service point expecting a full response to their information needs, or are they coming up and asking directional questions with the expectation that they need to be referred to a reference or circulation desk? If a referral is the best answer for a complex question, is it being handled appropriately, with the user being directed to the service or collection they need on the first referral, or is the user being passed along to a reference desk by default, with the hope that someone there can assist the user? Is there a need for an abbreviated reference interview, or are users communicating their directional assistance needs in a precise manner? There is a significant body of literature that explores information-seeking behaviors, especially in the context of technology. Unfortunately, there is little in the professional literature that asks what contemporary, computerliterate users are seeking as they walk into the library building's front doors. Only by assessing what users are asking at that first service point is it possible for administrators to, first, determine if expectations are being met, and, second, make the necessary changes needed to develop the most appropriate and effective spatial configuration, training tools, and staffing models to improve this service experience. This article attempts to explore this issue by presenting qualitative data gathered on almost two thousand questions asked at the desk nearest the front door of a main library in a university setting during the first several weeks of the fall semester. It then introduces some library resource management and training issues that are part of implementing service improvement initiatives at this point of initial contact. The preliminary data from this study was presented as an American Library Association Annual Conference poster session in 2004. Based on the feedback from that presentation, the issue of quantitatively identifying what current users are actually coming into the library seeking at the first point of contact, and how they ask for it, is of interest to libraries of all types and sizes.

\section{DATA COLLECTION ENVIRONMENT}

The data for this study was collected at the desk at the entrance to Texas A\&M University's Evans Library. This is the main library of a central library complex, with several connected buildings that serve the majority of the university population of 50,000 to 60,000 individuals. The Evans Library and adjacent Evans Annex each have six floors, 
with a cumulative assignable space of approximately 410,000 square feet. The two buildings are connected by a fourth-floor bridge. The sprawling campus has three smaller, subject-focused libraries on the west side of campus that serve the medical and veterinary programs, the college of business, and the political science and economics departments. Separate humanities and social sciences, and science and engineering reference units are located within the main complex, along with discreet service desks for circulation, reserves, current periodicals, interlibrary services, media (A/V) services, and microforms. Additionally, at the time of this study, the library had three tenant services, a university copy services satellite called the Copy Center, the thesis and dissertation office, and a newly created university writing center.

In this library, the desk nearest the door is called the loss prevention specialist, or LPS, desk. It is a multifunctional desk intended to answer basic facility and service directional questions, monitor incoming students for compliance with the library's food and drink policy, and respond to any activation signals from the security gates at the exit door. After 5 P.M., the desk occupants also serve as the facility proctors and oversee any facilities maintenance emergencies or security issues. The desk was not designed to look or function as a reference desk. Intended to provide a quick directional answer and maintain attention to the entrance and exit doors, the LPS desk configuration included neither a computer workstation to search the Web site or online catalog, nor a place for a patron to sit down while asking a question. It was expected that most users with nondirectional, research, or service questions would recognize this and bypass the LPS desk to go directly to the larger, more visibly equipped circulation or reference service points. At one time, the information services and security functions at the desk were distinct, with each service having its own counter area and staffing. Senior student workers and library staff covered the information desk, and loss prevention specialists were responsible for building and security issues. However, shortly after a 1999 building renovation, the two functions were combined to a single desk and staffing model. At that time, it was believed that most questions that initiated at this desk were directional in nature and could be answered in a straightforward manner or accurately referred to the humanities and social sciences reference desk by LPS employees. Anecdotal evidence during the past few years appeared to support this assumption. Though the humanities and social sciences reference desk was some distance away, it was in a direct line of sight from the LPS desk at the opposite end of a main corridor. Figure 1 shows a layout of the library's first floor. Obviously, the biggest challenge associated with a referral is that the user understands why they are being referred and will follow through on their request at the other service point.

The LPS unit was initiated in the mid-1990s, and staffing was originally modeled after a store greeter concept, with limited extra security patrolling responsibilities. In addition to sitting at the desk near the entrance, LPS employees patrol the building to encourage proper conduct, monitor compliance with the food and drink policy, and check perimeter exits for building access security. The basic position description and experience requirements can be seen on the Texas A\&M University Human Resources Web site at http:// employees.tamu.edu/managers/positions/Pay Plans/ByTitle.aspx. The staff members are a very diverse group that come from a variety of backgrounds. Several of the loss prevention specialists have retired from other careers and work parttime. Very few have personal higher education experience as a student or instructor, or extensive technology skills.

\section{GATHERING THE DATA}

The data gathered for this study was primarily qualitative in nature. Each time a library user came to the desk with a question, the staff member answering it was asked to record the time, date, what the library user asked for, and how the staff member responded. Staff members were encouraged to write the questions down using words as close as possible to what the patrons had used. Figure 2 shows the layout of the quarter-page form used for each question. As some loss prevention specialists had questioned whether they were being tested by what they write down, they were told not to sign or initial the questions. To encourage participation,

Figure 1. Layout of the Library First Floor

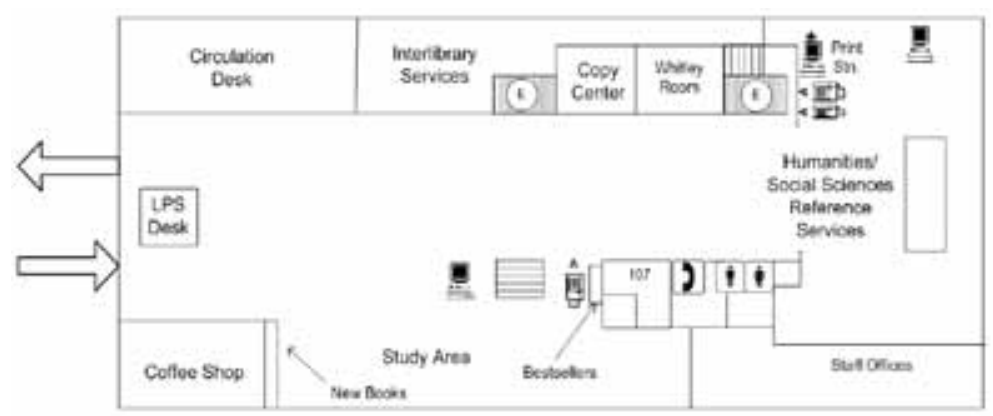


it was explained that the data would be used to better identify where training was needed, not as an evaluation of any one individual's knowledge. Also, the data were entirely anonymous with respect to the identities of the actual library users.

The questions were transcribed into a Microsoft Access database by student workers. Given the hurried nature in which questions were sometimes written down, interpreting and reading handwriting was sometimes a challenge and worked best with a minimal number of different transcribers. Access queries were used to identify time and date patterns of user needs and when the most questions were being asked. The author originally intended to use Atlas.ti to perform qualitative analysis on the results, but found that by capturing each question discreetly, most of the questions were sufficiently straightforward that basic grouping and sorting techniques were more effective. In cases where a library user had asked multiple questions in the same transaction, the questions were split out and each treated as a unique query during the grouping and sorting process. To determine the accuracy or correctness of the answer, the author relied upon her own eight years of experience in various public service and middle manager roles within the library, with the assistance of senior reference services colleagues for more ambiguous responses.

\section{ASSESSING THE QUESTIONS}

During the first four weeks of the fall 2003 semester, 1,890 discrete questions were recorded in 1,781 library user transactions. In approximately one hundred cases, the library user followed up

Figure 2. Form Used to Gather Data

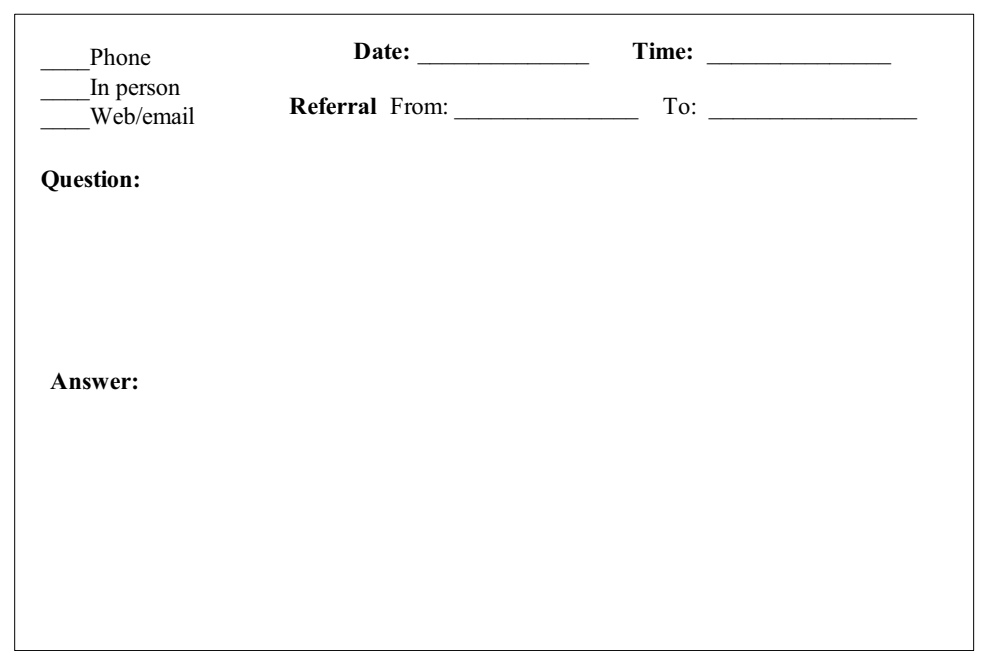

with a second or third question as part of a single transaction. For discussion and reporting purposes, one percentage point equates to nineteen separate questions by library users.

The first aspect of the data that was examined was the accuracy and correctness of the answers and an assessment of what the majority of users were seeking at this service point. The level of correctness of the LPS staff responses to the questions was extremely high, with 74.3 percent of the questions answered correctly. Only 3.8 percent were answered wrong, with the user sent to the wrong place or told a service was not available when, in fact, it was. However, a significant area of concern from a library administrative perspective is the remaining 21.9 percent. Of these, 10.7 percent were computer-related questions that frequently required a more complete answer than the one the user received at the front desk. Another 11.2 percent fell into a gray area where it was impossible to tell from what the LPS staff member had written whether the user was actually sent to the correct service point or not. In these cases, the staff member had given a response to what was actually a broad or vague question without asking sufficient follow-up questions to verify the actual need and may have directed the user based on incorrect assumptions. Figures 3 and 4 illustrate a broad breakdown of the types of questions that were asked.

\section{Giving Correct Directions}

Undoubtedly, the high accuracy rate is in part due to the simple nature of many of these questions. The majority of these questions were repetitive and could be answered in a routine directive manner based on general library and campus knowledge or using a map or handout. Directions to the copy center represented 12.4 percent of the transactions. Library users were evenly split between those that asked for the copy center by name and those that asked for a course packet, blue book, color photocopy, or other service offered by this center. On a related topic, 4.1 percent of the requests for directional assistance were from students seeking information on the location and use of self-serve photocopiers. While most simply asked where to find a photocopier, some did seek information on how the prepaid copy card system worked, and a few users reported copier malfunctions. One set of frequently asked questions, especially during the first two weeks of class, were directional needs for buildings and services outside of the library, representing 8.4 percent of the overall question total. The bulk of these requests were answered by pro- 
viding users with a campus map with the named building spotted for them. In addition to asking for buildings by name or course schedule abbreviation, 2 percent also asked for service location assistance, such as where the nearest automated teller machine (ATM) was, where they could receive a fax, and where to find something to eat. Two other named library tenant services represented sixty-one questions, with 2.7 percent seeking the writing center, and 0.5 percent needing directions to the thesis and dissertation office. Another 5.6 percent of the questions involved users asking about future library hours or when the library would be closing, and 1.1 percent represented students looking for an on-campus job. Finally, 3.1 percent of the questions were from users with facility directional questions, such as public phones, restrooms, and elevators. Combined, these groups of questions represented a total of 37.9 percent, or slightly more than one-third of the total questions asked. This confirms that many library users think of a library as more than just a repository of reading and scholarly research materials, but actually as a resource for many different information needs and personal services.

The two other large areas of the correctly answered directional questions were specifically targeted toward more typical library services and resources. For 16.2 percent, or 307 questions, the library user asked for directions to a named library service point, staff member, or collection. As an example, 2.9 percent asked for the instructional classrooms or class media viewing rooms based on a room number they had been given, presumably by their course instructor. The course reserves department and map room also were popular requests. Only ten library users, or 0.5 percent, asked for a reference desk with a subjectbased qualifier to indicate whether they needed science and engineering or humanities and social sciences assistance. A considerably larger number of users, 23.65 percent, asked for assistance without any indication of knowing what unit in the library would be most appropriate. This also was a characteristic of many of the questions that the LPS staff failed to answer correctly or completely, and is discussed in detail further on. Many library users asked material-related questions, using descriptive terms to explain what they needed. Instead of "reserves," they used terms such as "old exams," "class notes," or "stuff my professor put in the library." For the media services unit, library users asked, "Where are the videotapes to check out?" "Where do I see my geography movie?" and "Where can I find the teleconferencing videos?" Instead of asking for circulation, 3.3 percent asked
"Where/how can I check out a book?" "Where do I pay a fine?" "Do I use my student ID to check out a book?" or "Where do I return books?" One library jargon term that did come up in the natural language questions relating to circulation operations, was "recall," both in terms of placing a request and picking up a recalled book. Supporting the concept of library as place, questions on how to reserve group study rooms and where to find quiet study areas also were common requests, making up 2.5 percent of the questions, especially into the third and fourth week of the academic term. One consistent aspect of all of these questions was that they were still fairly straightforward to answer and generally directional in nature. They could be answered by a staff member with basic knowledge and understanding of the type of services offered around the library, as gained and retained from general tours or orientations. Similarly, the user asking the question was expecting a referral type of answer. For a user making an inquiry on the location of a particular call number, which represented 3.2 percent of the questions, the expectation was

Figure 3. Breakdown of Correctly Answered Questions

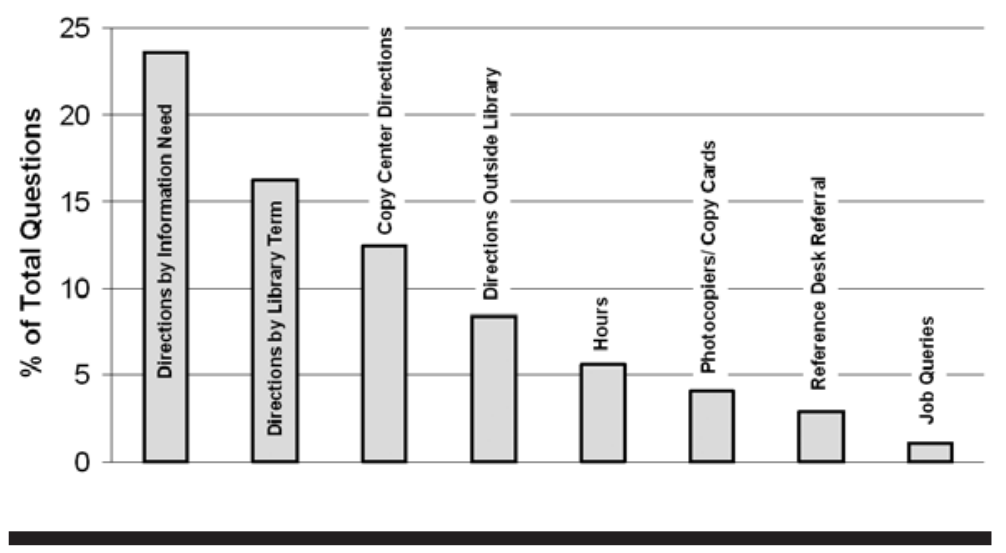

Figure 4. Breakdown of Problematic Questions

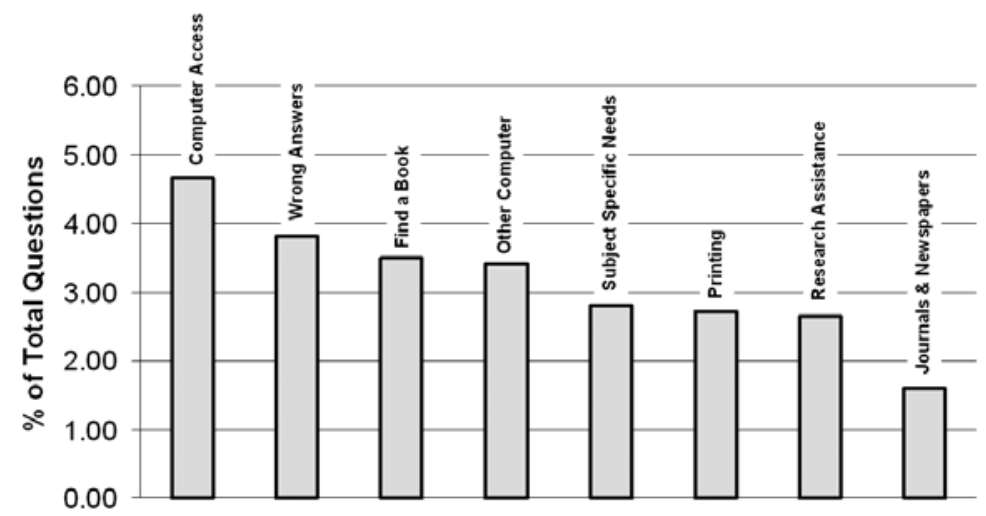


satisfied by the users being told a place to go and handed a stack guide or map that reminded them en route of where they were going. The situation is more challenging when the patron indicates a need for assistance with actual research or a computer related problem.

\section{The Challenge of Research Related Requests}

Though it is always gratifying for an institution to learn what staff members are doing right, and having a 74 percent accuracy rate definitely indicates positive things about the current training models, which incorporate tours and handouts, there always is room for improvement. With this in mind, it is actually more helpful to closely examine the questions that were not answered correctly or effectively. In actuality, there were only twelve questions where the library user was sent away from the library with totally wrong information. However, the remaining 25.5 percent pointed to some fundamental unresolved issues in defining the expectations of the front door service point and those who staff it. Many of these questions were fairly complex in nature.

Of the 3.8 percent of the questions that were answered wrong, more than two-thirds represented a pass-the-buck perspective: if in doubt, send the user to the nearest reference desk. While it is probable that the misdirected library user was given more correct information by the senior staff and librarians at the humanities and social sciences reference desk, the person was inconvenienced by having to make an intermediate stop between the point of first engaging a library staff member and getting to the correct service point with their information needs. With time a valuable commodity in today's society, the patience for this sort of detour is considerably lower than in previous years. Some library users undoubtedly felt even more frustrated because they had to retrace their steps back to the front of the building to talk to interlibrary services or circulation staff to get the assistance they needed. Another area of confusion for the LPS staff related to their inability to understand the distinctions between science and engineering areas and humanities and social sciences areas, current issues versus backfiles of journals, and the way a textbook might be a part of different library collections.

Another area of concern was lack of follow-up on broad initial questions to make sure the user was being sent to the correct desk or portion of the collection. Many users with the general question of "Where do I go to do a search for a book?"
"How do I look up a call number?" or "Does the library have [this] book?" were routed to the humanities and social science reference desk without any follow-up by the LPS staff to determine if they were looking for material in a particular topical area, such as engineering or education, or querying by the LPS staff as to whether the user was familiar with online catalogs. Similarly, those seeking magazines or journals were sent in an inconsistent manner to either the current periodicals desk or the humanities and social science reference desk. As with books, these questions were broadly phrased, such as "Where are the newspapers and magazines?" "I need some journal articles," and "How do I find periodicals?" Those with such questions were sent directly to the current periodicals desk with little engagement to determine if the user already had a journal title and whether current or older issues were needed. One curious observation from the data was that library users that started their request with the word "where" were sent more frequently to the specific area or service desk associated with the resource. In directing the user in this manner, the staff member was making an implied assumption that the user did not need the additional guidance or instruction offered by reference services. Asking "Where are the newspapers and magazines?" and "Where are the books?" caused one user to be sent to the current periodicals department and another into the stacks with a call number guide. The students who phrased their question beginning with the words "How do I ...." or "I need to find ...." were usually sent to the humanities and social sciences reference desk with the implicit assumption that the user required more personalized, in-depth assistance. The humanities and social sciences reference also was the frequent referral destination for those students that inserted extra words and qualifiers, such as "Where are the architecture books?" or "I need articles on test tube babies." Another example of this was when the person combined a subject area with a genre or format qualifier, such as "Where do I find my anthropology syllabus?" "I need a physics textbook," or "Where are the animal research archives?" It was fairly obvious that the LPS staff were not able to differentiate well between the two subject-based reference services or address complex questions at anything more than a broad level. If someone specifically used the word engineering or a simple common science term, such as biology, they would be referred correctly. But those that actually tried to explain their topic in detail or referenced potentially interdisciplinary areas, such as genetics, the environment, or architecture, were referred to the humanities 
and social sciences reference by default. Unfortunately, this lack of follow up was also the case for the twenty users that asked explicitly for "the reference desk."

\section{Embracing Technology}

The last significant group of problematic questions were the 10.7 percent that related to technology. These questions came from computer-literate users who entered the library with expectations of finding computer resources and support. The two most frequently asked questions from this group were "Where is a computer I can use?" and "Does the library have a wireless Internet connection?" In their basic form, these were fairly straightforward questions to answer by directing the user to one of several computer pods in the complex or saying "Yes, the building does have a wireless network." However, the difficulties came with the next stage of questions that came after these responses. The user often would follow up by then asking for clarification on what to use as a login and password to access the library computers, and how to then get to specific named electronic resources. The users seeking a wireless connection often asked for technical details on what was required to connect their personal laptop to the wireless network, or sought troubleshooting assistance if something was not working correctly. The latter two areas were ones that had never been incorporated into the training for any of the library service points, much less the one intended to provide basic directional assistance. Another large group of technology questions, more than fifty, were centered around printing, which required users to purchase a copy card, go to the appropriate networked printer station based on where the computer they had been working on was located, and follow directions on selecting and printing their particular document. This was not a trivial process to try and explain on the fly, and many of the library users were sent to the default humanities and social sciences reference desk for assistance. One curious phrasing of a type of question stood out from the others and caused significant confusion. The user would ask for the location of a virtual electronic service, such as "Where are e-reserves?" "Where are digital dissertations?" or "Where is DeliverEdocs?" (the library's to-the-desktop ILS service). Often the LPS staff member would refer the person to what sounded like the closest service desk match, such as the course reserves desk for the e-reserves service, not realizing the student was asking not "Where?" but "How do I access . . . ?" A preliminary review of the data at the end of the third week pointed out the confusion associated with these questions. To address them, a one-page handout was prepared to help the LPS staff answer them more effectively. General feedback from staff at multiple service points indicated that this resource was helpful, and many copies of the handout have been distributed to users at the point of need, giving them links to detailed technical information and providing instructions users can take with them to the networked printing stations.

\section{WHAT DOES THIS MEAN?}

There are several key things this data tell us about defining, designing, and staffing service points in a library as well as what to provide in the nature of training and resource support. Even as the bulk of questions faced by staff at the desk nearest an entrance are still directional in nature, a significant percentage have become more sophisticated and require a basic understanding of the reference interview and details of library information services and resources provided to the user population. Depending on the nature of the library, answering these questions might require local community knowledge, an academic background, or significantly more expert training to answer correctly. As technological resources continue to grow and the library is seen as the gateway to this knowledge for increasingly diverse user populations, it is likely that the quantity of more complex questions will also grow, especially as related to technology and computer troubleshooting. In a perfect world, budgets are no object, and every desk can be staffed with senior staff and librarians trained to answer all questions. Reality is much different and requires establishing reasonable expectations, developing targeted training and support tools, and working to make the library, as a whole, less jargon-laden and confusing to users. Even as a library may have a goal of every question answered on the first interaction or with only one referral, the broad range of topics and the specificity of some questions represented in this data tell us that the scope of knowledge and services contained in contemporary libraries, combined with the tendency of users to communicate their needs in natural language, make it an ideal that will never be fully achieved.

In light of this, library management has several options for improving the service quality to users in their initial contact. One possibility might be to maintain a desk that incorporates minimally trained staff but then modify user expectations through desk configuration or signage so that users recognize that the service point is designed only 
for directional assistance and referral. Another option for an administration that wanted to make partial improvements in service while maintaining the current staffing model would be to provide additional training and targeted, point-of-need handout resources to supplement staff member knowledge and effectiveness. However, within an institution that has a career ladder structure, union, or civil service, additional training and increased scope can still equate to reclassifying the position and having to raise the pay scale. Also, if the library user knowledge expectations outpace the base knowledge of the staff member, such as occurred on the wireless Internet connection and follow-up specific resource access questions, training alone will not resolve underlying issues of trying to turn a high school graduate into a research scholar or computer technician. Another solution is to redefine the staffing altogether and, rather than use volunteers or minimally trained, highturnover staff at the desk nearest the entrance, go with a more expert, permanent, budgeted staff. The biggest drawback of this option is that based on the data from the study, for each sophisticated question that actually uses their expertise, the staff member will be answering three other boring, basic directional questions that any volunteer or student worker with basic training can do. A final option is to rethink the entire library layout and resource organization so that similar groups of resources and services sought by users are near each other-thereby minimizing the inconvenience of the referral process. This is not something that can usually be accomplished overnight and requires planning with an eye to the institution's change leadership, facilities, and financial base. In truth, none of these options are perfect, and the decision of which is most appropriate for a particular library will vary depending on the complexity of services being provided, available resources, and the user community's expectations. In many cases, blending these options with elements from each may be the best solution for a complex library environment, such as that found in a major metropolitan area or large academic institution.

For the library where the study was conducted, several changes have been implemented based on the data, with varying degrees of success, and the environment continues to evolve to address these issues. A new training program on conducting an information interview that incorporates basic elements of the reference interview is being developed. There is managerial recognition that some individuals among the loss prevention specialists will be able to incorporate the training easier than others. An LPS vacancy offered the opportunity to explore alternative staffing models, and the position was refilled with bright student workers in disciplines with strong academic research experience. Unfortunately, the student workers subsequently expressed significant frustration with the overall tedium, sporadic pace of questions, and lack of mental challenge associated with sitting at the LPS desk. This model also did not meet the needed scheduling flexibility to provide coverage for the extended final exam building hours. The latest model, which seems to be successful, provides daytime LPS coverage by circulation student employees rotated on an hourly basis to minimize the tedium. It maintains a dedicated staff coverage model still in place for nights and weekends. A reclassification process that shifted all of the night and weekend LPS positions to the entry level of the library staff career ladder was implemented September 2006, with follow-up training to broaden their desk service skills. The reclassification defines the customer service emphasis of these positions and allows for future personal growth opportunities. The various textbook and journals and newspapers services have been relocated from four separate spaces into one space that combines course reserves, the library's university textbook collection, current journals and newspapers, microform backfiles, and a dedicated service desk where staff can further assist users with guidance to the general collection, which includes some textbook material and integrated bound journals, and electronic journal resources. Most significantly, a reorganization of the science and engineering and humanities and social sciences units was implemented. The reorganization maintained some of the expert librarian elements of the previous subject-based structure, but placed both reference service operations in the same physical space with a single main reference desk and shared staffing. Within the next couple of years, the author anticipates doing a follow-up assessment to determine the true impact of such significant changes on service quality at the desk nearest the door and the critical first impression interaction.

\section{CONCLUSION}

This study clearly illustrates that most contemporary library users do not seek services based on a library department name, professional jargon, or resource branding. Instead, they phrase their queries in the context of their end product needs or the problem being faced. As such, those working at any desk, including the one nearest the door, need to understand the actual services behind a departmental name and be able to apply a basic form of the information or reference interview to 
make an appropriate referral at the point of initial contact. In an academic library setting, depending on the organizational structure and spatial layout, an understanding of academic disciplines and interdisciplinary research topics also may be a requirement. The growth of computers as societal information tools causes a corresponding growth in user expectations for assistance in using and troubleshooting them. It is important that library administrations recognize the importance of the first point of contact between users and a library representative. This requires: (1) defining the purpose of the service point nearest the door; (2) clarifying both staff and user expectations on the scope of assistance it provides; (3) support resource development consistent with this definition; and (4) assessment of how effectively this is meeting user needs. As shown here, anecdotal reflections may have some substance and accuracy, but may not reflect a full picture of user needs.

\section{References}

1. Jane P. Kleiner, "The Information Desk: The Library's Gateway to Service," College \& Research Libraries 29
(Nov. 1968): 496-501; Larry E. Harrelson, "Large Libraries and Information Desks," College \& Research Libraries 35, no. 1 (1974): 21-27.

2. Dennis W. Dickinson and Ruta Pempe, Information Desk: Testing a Prescribed Model in the Local Environment (Bethesda, Md.: ERIC Document Reproduction Service, ED 168 585, 1978).

3. C. Brigid Welch, ed., SPEC Kit 172: Information Desks in ARL Libraries (Washington, D.C.: Association of Research Libraries Office of Management Services, 1991).

4. Vicki Coleman et al., "Tiered Reference Services: A Survey," Reference Librarian 59 (1997): 25-35.

5. Karen J. Graves, "Implementation and Evaluation of Information Desk Services Provided by Library Technical Assistants," Bulletin of the Medical Library Association 86, no. 4 (1998): 475-85.

6. Michael Heine, Ian Winkworth, and Kathryn Ray, "Modeling Service-Seeking Behavior in an Academic Library: A Methodology and Its Application," Journal of Academic Librarianship 26, no. 4 (2000): 233-47.

7. Pat Flanagan and Lisa R. Horowitz, "Exploring New Service Models: Can Consolidating Public Service Points Improve Response to Customer Needs?" Journal of Academic Librarianship 26, no. 5 (2000) 329-38; Allison Cowgill, Joan Beam, and Lindsey Wess, "Implementing an Information Commons in a University Library," Journal of Academic Librarianship 27, no. 6 (2001): 432-39. 